\title{
Use of magnetic resonance imaging to detect occult spinal dysraphism in infants
}

\author{
Brent R. O'Neill, MD, ${ }^{1}$ Danielle Gallegos, MD, ${ }^{4}$ Alex Herron, BS, ${ }^{1}$ Claire Palmer, MS, ${ }^{3}$ \\ Nicholas V. Stence, MD, ${ }^{2}$ Todd C. Hankinson, MD, ${ }^{1}$ C. Corbett Wilkinson, MD, ${ }^{1}$ and \\ Michael H. Handler, MD ${ }^{1}$
}

Departments of ${ }^{1}$ Neurosurgery, ${ }^{2}$ Radiology, and ${ }^{3}$ Pediatrics, Children's Hospital Colorado, Aurora; and ${ }^{4}$ Department of Medicine, Saint Joseph Hospital, Denver, Colorado

OBJECTIVE Cutaneous stigmata or congenital anomalies often prompt screening for occult spinal dysraphism (OSD) in asymptomatic infants. While a number of studies have examined the results of ultrasonography (US) screening, less is known about the findings when MRI is used as the primary imaging modality. The object of this study was to assess the results of MRI screening for OSD in infants.

METHODS The authors undertook a retrospective review of all infants who had undergone MRI of the lumbar spine to screen for OSD over a 6 -year period (September 2006-September 2012). All images had been obtained on modern MRI scanners using sequences optimized to detect OSD, which was defined as any fibrolipoma of the filum terminale (FFT), a conus medullaris ending at or below the L2-3 disc space, as well as more complex lesions such as lipomyelomeningocele (LMM).

RESULTS Five hundred twenty-two patients with a mean age of 6.2 months at imaging were included in the study. Indications for imaging included isolated dimple in 235 patients (45\%), asymmetrically deviated gluteal cleft in $43(8 \%)$, symmetrically deviated (Y-shaped) gluteal cleft in $38(7 \%)$, hemangioma in $28(5 \%)$, other isolated cutaneous stigmata (subcutaneous lipoma, vestigial tail, hairy patch, and dysplastic skin) in $31(6 \%)$, several of the above stigmata in 97 $(18 \%)$, and congenital anomalies in $50(10 \%)$.

Twenty-three percent (122 patients) of the study population had OSD. Lesions in 19\% of these 122 patients were complex OSD consisting of LMM, dermal sinus tract extending to the thecal sac, and lipomeningocele. The majority of OSD lesions (99 patients [81\%]) were filar abnormalities, a group including FFT and low-lying conus.

The rate of OSD ranged from $12 \%$ for patients with asymmetrically deviated gluteal crease to $55 \%$ for those with other isolated cutaneous stigmata.

Isolated midline dimple was the most common indication for imaging. Among this group, 20\% (46 of 235) had OSD.

There was no difference in the rate of OSD based on dimple location. Those with OSD had a mean dimple position of 15 $\mathrm{mm}$ (SD 11.8) above the coccyx. Those without OSD had a mean dimple position of $12.2 \mathrm{~mm}$ (SD 19) above the coccyx $(p=0.25)$.

CONCLUSIONS The prevalence of OSD identified with modern high-resolution MRI screening is significantly higher than that reported with US screening, particularly in patients with dimples. The majority of OSD lesions identified are FFT and low conus. The clinical significance of such lesions remains unclear.

https://thejns.org/doi/abs/10.3171/2016.8.PEDS16128

KEY WORDS spinal cord tethering; occult spinal dysraphism; infants; tethered cord syndrome; cutaneous stigmata; congenital anomalies; fibrolipomas; lipomeningocele; spine

ABBREVIATIONS ARM = anorectal malformation; DST = dermal sinus tract extending to the thecal sac; FFT = fibrolipoma of the filum terminale; $\mathrm{LMM}=$ lipomyelomeningocele; OSD = occult spinal dysraphism; TCS = tethered cord syndrome; US = ultrasonography; VACTERL = vertebral anomalies, anal atresia, cardiac defects, tracheoesophageal fistula and/or esophageal atresia, renal anomalies, and limb defects.

SUBMITTED March 22, 2016. ACCEPTED August 30, 2016.

INCLUDE WHEN CITING Published online December 2, 2016; DOI: 10.3171/2016.8.PEDS16128. 
$\mathrm{O}$ CCULT spinal dysraphism (OSD) refers to a collection of anatomical abnormalities of the spine that attach the spinal cord to surrounding dura mater, bone, and soft tissues. If the pathological attachment applies tension to the spinal cord, as can occur with axial growth, normal function of the lower spinal cord can be disrupted, resulting in tethered cord syndrome (TCS). ${ }^{12,25}$ This syndrome is the clinical manifestation of spinal tethering and can include dysfunction of the bowel and/or bladder, pain in the back and legs, orthopedic deformity, weakness, spasticity, and loss of sensation. . $^{3,8,11,12}$

In this paper, the term "OSD" refers exclusively to lesions that have some potential to cause symptoms of TCS. Occult spinal dysraphism encompasses a spectrum of congenital anomalies ranging from complex lesions (for example, lipomyelomeningocele [LMM] and myelocystocele) to subtle anatomical abnormalities (for example, fibrolipoma of the filum terminale [FFT] or a low-lying conus medullaris). The association of clinical symptoms with each of the specific subtypes of OSD is not well understood. Bony defects of the spine or soft tissue defects overlying the spine are excluded from our definition of OSD for the purposes of this paper. We chose to avoid the terms "spinal cord tethering" and "tethering lesion" because they imply pathology when, in fact, the majority of infants studied here were asymptomatic and not diagnosed with TCS. The natural history of subtle OSD lesions identified in a number of our patients is incompletely understood, and their significance is considered controversial.

Occult spinal dysraphism has been linked to several midline cutaneous markers and to congenital anomalies such as anorectal malformations (ARMs) ${ }^{7}$ and the cooccurrence of vertebral anomalies, anal atresia, cardiac defects, tracheoesophageal fistula and/or esophageal atresia, renal anomalies, and limb defects, also known as the VACTERL association..$^{21}$ Cutaneous stigmata associated with OSD include dimples, hemangiomas, subcutaneous lipomas, hairy patches, deviated gluteal fold, and skin appendages. . $^{3,4,9,10,15,16,18,26,27}$

The true prevalence of OSD has not been established. Magnetic resonance imaging is the gold standard for diagnosing the disorder but is expensive and time consuming and often requires the patient to undergo sedation or general anesthesia. While spinal ultrasonography (US) has logistical advantages over MRI, its sensitivity and specificity relative to MRI is not known, particularly for detecting lesions on the mild end of the OSD spectrum, such as an FFT. Perhaps more importantly, the natural history of tethering lesions is poorly understood; therefore, the utility of early diagnosis and prophylactic detethering surgery in asymptomatic patients remains unclear.

The widely discrepant opinions held by pediatric neurosurgeons on these topics have been highlighted in 2 recent surveys. In a 2010 survey that asked about imaging recommendations for simple dimples (defined as "soft tissue depressions appearing up to $2.5 \mathrm{~cm}$ above the anus or within coccygeal proximity"), $48 \%$ of the responding neurosurgeons recommended no imaging, 30\% recommended US, and 22\% recommended MRI. ${ }^{22}$ A similar level of disagreement was demonstrated in response to questions about hemangioma and deviated gluteal fold. A 2004 survey (published in 2006) of pediatric neurosurgeons showed a lack of consensus about undertaking spinal detethering surgery in a variety of clinical scenarios. ${ }^{24}$

A number of investigators have reported the results of lumbar US screening of infants with various putative predictors of OSD. ${ }^{1,4,10,13,15,16,18,23}$ The results of modern high-resolution MRI screenings of similar infants have not been well studied. In the current retrospective analysis from a single institution, we examine the results of screening for OSD with modern high-resolution MRI optimized to detect spinal tethering lesions.

\section{Methods \\ Study Population}

After appropriate institutional review board approval was obtained, the radiology database at Children's Hospital Colorado was queried for all noncontrast lumbar MRI studies performed between September 2006 and September 2012 to screen for OSD in patients under 1 year of age. Our pediatric neurosurgery practitioners typically use MRI as the initial and only test to evaluate for OSD. This approach has disseminated to a number of the other hospital-affiliated and community practitioners.

All imaging was performed on a 1.5-T Siemens Avanto MRI unit. Initial large field of view, sagittal T2-weighted imaging of the entire spinal column was performed for vertebral body counting. Lumbar spine imaging with sagittal and axial T1- and T2-weighted sequences was performed from T-12 through the coccyx. All sequences had submillimeter in-plane spatial resolution, slice thicknesses ranging from 3 to $4 \mathrm{~mm}$, and skips of $0.3-0.5 \mathrm{~mm}$. All images were digitized and reviewed on high-resolution monitors with magnification capability to provide submillimeter resolution. Typically, non-fat-saturated T1-weighted images are obtained in all cases as they optimize detection of FFT given the high contrast of fat (T1 bright) against surrounding CSF (T1 dark).

Lumbar MRI studies done with other MRI of the neuraxis were excluded, as were studies done for reasons other than assessing for OSD. Medical records including radiology reports of the relevant imaging studies were reviewed. Collected data included age at imaging, provider ordering the imaging (dichotomized to neurosurgery and other), imaging results, surgical intervention, and indication for imaging.

Indication for imaging was separated into 7 categories including the presence of an isolated sacral dimple, isolated hemangioma, isolated asymmetrically deviated gluteal cleft, isolated symmetrically deviated (Y-shaped) gluteal cleft, "other isolated cutaneous stigmata," a combination of 2 or more of any of the cutaneous markers listed above ("multiple cutaneous stigmata"), or a congenital malformation/syndrome or symptom complex associated with tethering (including VACTERL association, imperforate anus, caudal regression, developmental or motor delay, neurogenic bladder, or other syndromic abnormalities). The "other isolated cutaneous stigmata" group included patients with subcutaneous lipoma, dysplastic skin, vestigial tail, or hairy patch; these categories were initially 
collected separately, but because of the small numbers in each, we combined the categories for analysis. Determining the indication for imaging was based on a review of available clinic notes.

A board-certified pediatric radiologist with experience in reading spinal MRI read all MRI studies. We reviewed the generated imaging reports to determine the presence of OSD, as defined below, and the position of the conus medullaris. If the conus position was not specified on the imaging report, the image itself was reviewed to determine the position. Filar cysts were categorized as a normal variant. Other lesions of the spine not associated with tethering, such as blunted conus medullaris, soft tissue abnormalities, and bony anomalies, were not recorded.

The definition of OSD used in this study was intentionally inclusive to capture all radiographic abnormalities that potentially reflect spinal tethering regardless of clinical significance. Low-lying conus (at or below the L2-3 disc), FFT of any size, and thickened filum terminale $(>2$ $\mathrm{mm}$ ) without lipoma were all included in the definition of OSD, as were more complex abnormalities such as LMM, lipomeningocele, dermal sinus tract extending to the thecal sac (DST), myelocystocele, and split cord malformation. Segmentation abnormalities, incomplete fusion of the laminae, subcutaneous lipomas, and other bony and soft-tissue defects that do not cause TCS were not recorded or included in our definition of OSD.

Because the natural history of especially the very mild end of the OSD spectrum is unknown and in many instances can be benign, those cases with FFT, thickened filum without fibrolipoma, and low-lying conus in isolation or in combination were categorized as "filar abnormalities." All other tethering lesions were categorized as "complex OSD."

In patients with a sacral dimple, the location of the dimple in relation to the tip of the coccyx was measured on the MR image. The distance between the dimple and the tip of the coccyx was measured along a line parallel to the skin surface of the back, above the buttocks to eliminate any effect of thicker soft tissues separating the coccyx from the skin surface (Fig. 1). The dimple location was routinely marked at the time of imaging by taping a vitamin E capsule over the dimple. These skin markers aided in identifying the dimple location on the MR image. Studies in which either the dimple or the tip of the coccyx could not be visualized were excluded from further analysis.

A number of investigators have examined the position of a dimple as a predictor of OSD and generally concluded that lower dimples are benign. A low dimple position has been defined as within $25 \mathrm{~mm}$ of the anus, as within the gluteal crease, or as a coccygeal pit rather than a sacral dimple. ${ }^{1,15}$ We chose the tip of the coccyx as the reference point for dimple location in the current study because it could be reliably and precisely identified on MRI. The top of the gluteal crease and the anus were more difficult to precisely define on images.

In the patients who had undergone both US and MRI, the results were compared. All data were collected in a REDCap (Research Electronic Data Capture) database and analyzed.

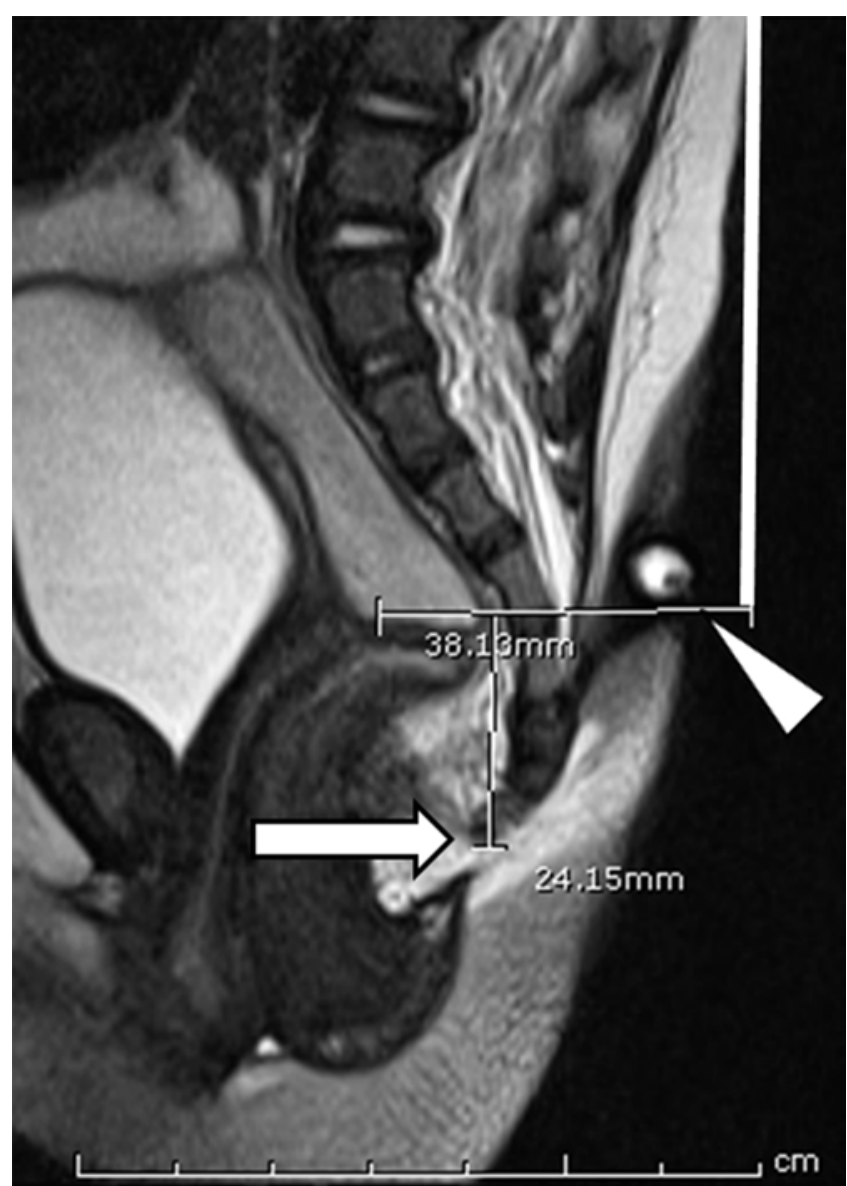

FIG. 1. Measurement of dimple location relative to the coccygeal tip. Arrow indicates the tip of the coccyx. Arrowhead indicates location of the dimple on the skin surface, which is marked by a vitamin E capsule. The thick plumb line is parallel to the skin surface of the back. The measurement (24 $\mathrm{mm}$ in this case) is taken parallel to the plumb line.

\section{Statistical Analysis}

Between-group demographic characteristics were compared using chi-square tests and 2-sample t-tests for categorical and continuous outcomes, respectively. Chisquare tests were used to compare the association between dimple location relative to the coccyx and tethering. In patients who had undergone US, results were confirmed using MRI as the standard reference. Specificity and sensitivity were calculated. We used $\mathrm{R}$ version 3.1.1 software (R Foundation for Statistical Computing, http://www.Rproject.org/).

\section{Results}

\section{Study Population}

Over the 6-year study period, 528 infants underwent noncontrast lumbar MRI. Six cases $(1.1 \%)$ were excluded as their MRI had been performed for reasons other than OSD, leaving 522 patients in the final analysis. The clinical reasons for imaging the excluded patients were concern for intraspinal hematoma following a lumbar puncture ( 2 cases), failed lumbar puncture (1 case), congenital kyphosis (1 case), open myelomeningocele (1 case), and pygopagus twins (1 case). 
TABLE 1. Demographics of study patients

\begin{tabular}{|c|c|c|c|}
\hline \multirow[b]{2}{*}{ Variable } & \multicolumn{2}{|c|}{ No. (\%) } & \multirow{2}{*}{$\begin{array}{c}p \\
\text { Value }\end{array}$} \\
\hline & OSD & No OSD & \\
\hline Total No. & $122(23.4)$ & $400(76.6)$ & \\
\hline \multicolumn{4}{|l|}{$\operatorname{Sex}(\%)$} \\
\hline Female & $65(53)$ & $173(43)$ & 0.07 \\
\hline Male & $57(47)$ & $227(57)$ & \\
\hline \multicolumn{4}{|l|}{ Age } \\
\hline Mean age in wks & 23 & 28 & $<0.01$ \\
\hline Patients under 3 mos of age & $22(18)$ & $30(8)$ & $<0.01$ \\
\hline Patients under 1 mo of age & $4(3)$ & $8(2)$ & 0.49 \\
\hline
\end{tabular}

Among the 522 study patients, 238 (46\%) were female and $284(54 \%)$ were male. Mean age at the time of imaging was 6.2 months. Fifty-two patients $(10 \%)$ were under 3 months of age, with only 12 of them (2\%) under 1 month old (Table 1).

The most common indication for imaging was a sacral dimple in isolation (235 cases [45\%]; Table 2). Other cutaneous stigmata that prompted imaging included an asymmetrically deviated gluteal cleft (43 [8\%]), a symmetrically deviated gluteal cleft (38 [7\%]), and a hemangioma (28 [5\%]). Thirty-one patients (6\%) had cutaneous stigmata other than those listed above, including subcutaneous lipoma (8 patients), skin tag (4), vestigial tail (2), dysplastic skin (2), or hairy patch (1). These markers were grouped together under the heading "other isolated cutaneous stigmata" for the remainder of this analysis. Ninety-seven patients $(18 \%)$ had more than 1 of the above cutaneous markers; among these patients were $82(84 \%)$ with a dimple. Forty patients (8\%) were scanned for congenital anomalies such as ARM (23 patients), VACTERL association (8), arthrogryposis (2), recurrent meningitis (1), and other congenital anomalies (6). Ten patients (2\%) were imaged for clinical suspicion of TCS.

\section{Potentially Tethering Lesions}

Overall, 23.4\% of the study cohort (122 patients) had OSD (Table 1). A sizable majority (99 [81\%] of 122) had filar abnormalities. The most common tethering abnormality found on imaging was FFT with a normal conus level (50 cases [41\%]), followed by low-lying conus alone
(32 [26\%]), LMM (19 [16\%]), FFT with a low-lying conus (17 [14\%]), DST (3 [2\%]), and lipomeningocele (1 [0.1\%]; Table 3). Among the 32 patients with an isolated low-lying conus, 12 had a conus at the level of the L2-3 disc, considered normal by some, 17 had a conus at the L-3 body, and 3 had a conus at the L- 4 body.

The group with the highest percentage of OSD was the category of other isolated cutaneous stigmata at 55\% (17 of 31 patients; Table 2). This group also had the highest proportion of complex OSD (LMM and DST) at 59\% (10 of 17). The second highest rate of OSD occurred among patients with congenital anomalies (18 [36\%] of 50), followed by patients with multiple cutaneous markers $(26$ [27\%] of 97). Isolated dimples, deviated gluteal clefts, and hemangiomas had an $18 \%$ (61 of 344) rate of abnormalities; however, the majority of these cases $(95 \%)$ were filar abnormalities. Two patients in this group had LMM, 1 with an isolated dimple $21 \mathrm{~mm}$ below the coccyx and 1 with an isolated hemangioma. One additional patient with an isolated dimple $31 \mathrm{~mm}$ above the coccyx was found to have a lipomeningocele. No DSTs were identified in the isolated dimple, deviated gluteal cleft, or hemangioma groups.

All patients with LMM, DST, and lipomeningocele underwent detethering surgery. Among the patients with filar abnormalities, $62 \%$ (61 patients) underwent detethering surgery. Those with an isolated low-lying conus were least likely to undergo operation; only $41 \%$ of this group (13 patients) had detethering surgery. Sixty-four percent of those with an FFT and a normal-level conus underwent surgery (Table 3 ). The decision to operate in all cases was made on an individualized basis, with the imaging results, surgeon's bias, and family's preference playing roles in the decision.

\section{Association Between Dimple Location and OSD}

There was not a significant association between OSD and dimple location relative to the coccyx when examining dimple level as a continuous variable $(\mathrm{p}=0.81)$. The mean dimple position in patients with OSD was $15.1 \mathrm{~mm}$ (SD 11.8) above the coccyx, while in those without OSD it was 12.2 (SD 19). The difference between the two was not significant $(p=0.25)$.

Patients with an isolated sacral dimple were split into tertiles based on dimple location (Table 4). Those with the

TABLE 2. Results by indication for imaging

\begin{tabular}{lccrr}
\hline \multicolumn{1}{c}{ Indication } & \multicolumn{1}{c}{ Total } & No OSD & Filar Abnormality & Complex OSD \\
\hline All indications & 522 & $400(77 \%)$ & $99(19 \%)$ & $23(4 \%)$ \\
\hline Sacral dimple (isolated) & $235(45 \%)$ & $189(80 \%)$ & $44(19 \%)$ & $2(1 \%)$ \\
\hline Hemangioma (isolated) & $28(5 \%)$ & $24(86 \%)$ & $3(11 \%)$ & $1(4 \%)$ \\
\hline Symmetrically deviated gluteal crease & $38(7 \%)$ & $32(84 \%)$ & $6(16 \%)$ & $0(0 \%)$ \\
\hline Asymmetrically deviated gluteal crease & $43(8 \%)$ & $38(88 \%)$ & $5(12 \%)$ & $0(0 \%)$ \\
\hline Multiple cutaneous stigmata & $97(18 \%)$ & $71(73 \%)$ & $18(19 \%)$ & $8(8 \%)$ \\
\hline Other isolated cutaneous stigmata* & $31(6 \%)$ & $14(45 \%: 14 / 31)$ & $7(22 \%)$ & $10(32 \%)$ \\
\hline Congenital anomaly $\dagger$ & $50(10 \%)$ & $32(64 \%)$ & $16(32 \%)$ & $2(4 \%)$ \\
\hline * Includes subcutaneous lipoma, skin tag, vestigial tail, hairy patch, and dysplastic skin. & &
\end{tabular}


TABLE 3. Types of OSD lesions identified

\begin{tabular}{lcccccc}
\hline \multicolumn{1}{c}{ OSD Lesion Type } & $\begin{array}{c}\text { Total } \\
\text { No. }\end{array}$ & $\begin{array}{c}\text { Surgically } \\
\text { Treated }\end{array}$ & Conus Position (no. of cases) & $\begin{array}{c}\text { Not Surgically } \\
\text { Treated }\end{array}$ & Conus Position (no. of cases) \\
\hline FFT & 50 & $32(64 \%)$ & & $18(36 \%)$ & \\
\hline Low conus, normal filum & 32 & $13(41 \%)$ & L-4 body 2, L-3 body 9, L2-3 disc 2 & $19(59 \%)$ & L-4 body 1, L-3 body 8, L2-3 disc 10 \\
\hline FFT + low conus (1 w/ meningocele) & 17 & $16(94 \%)$ & L-4 body 1, L-3 body 6, L2-3 disc 9 & $1(6 \%)$ & L-4 body 1 \\
\hline LMM & 19 & 19 & & 0 & 0 \\
\hline DST (2 w/ low conus) & 3 & 3 & & 0 & \\
\hline Lipomeningocele & 1 & 1 & & & 0 \\
\hline
\end{tabular}

lowest dimples, ranging from $24 \mathrm{~mm}$ below the coccyx to $3 \mathrm{~mm}$ above, had a $27 \%$ (19 of 70 ) rate of OSD. The middle tertile, ranging from 4 to $11 \mathrm{~mm}$ above the coccyx, had a 19\% (14 of 75) rate of OSD, and those with the highest dimples, ranging from 12 to $102 \mathrm{~mm}$ above the coccyx had a 16\% (12 of 76) rate of OSD. These differences were not significant $(\mathrm{p}=0.25)$. Fourteen dimples could not be measured because either the dimple or the tip of the coccyx was not visible on MRI (Figs. 2-6).

One group that trended toward a higher OSD rate was the few outliers with dimples more than $40 \mathrm{~mm}$ above the coccyx. Among these 8 patients, $5(62 \%)$ had tethering lesions.

Eighty-two patients had a sacral dimple associated with another cutaneous finding accounting for $26 \%$ percent of the dimple cohort. The associated cutaneous finding included symmetrically deviated gluteal crease in 39 (48\%), asymmetrically deviated gluteal crease in 13 (16\%), skin tag in $12(15 \%)$, hemangioma in $9(11 \%)$, and hairy patch in $9(11 \%)$. The OSD rate for the group was 23\% (19 of 82), which was not significantly different from the rate for the isolated sacral dimple group. None of the additional skin stigmata associated with a dimple was significantly more likely to predict OSD, but the small numbers limit any definitive conclusion on this point.

\section{Initiation of Referral for Imaging}

Seventy-nine percent of patients (252 of 317) harboring sacral dimples were referred for imaging by nonneurosurgical providers such as community pediatrics providers (144 [45\%]), Children's Hospital Colorado affiliated

TABLE 4. Association between dimple location and OSD

\begin{tabular}{|c|c|c|c|}
\hline Variable & OSD & $\begin{array}{l}\text { No } \\
\text { OSD }\end{array}$ & $\begin{array}{c}\mathrm{p} \\
\text { Value }\end{array}$ \\
\hline Total no. of cases & 45 & 176 & \\
\hline $\begin{array}{l}\text { Lowest dimples, } 24 \mathrm{~mm} \text { below- } 3 \\
\mathrm{~mm} \text { above the coccyx }\end{array}$ & $19(27 \%)$ & $51(73 \%)$ & 0.25 \\
\hline $\begin{array}{l}\text { Intermediate, } 4-11 \mathrm{~mm} \text { above the } \\
\text { coccyx }\end{array}$ & $14(19 \%)$ & $61(81 \%)$ & \\
\hline $\begin{array}{l}\text { Highest dimples, } 12-102 \mathrm{~mm} \\
\text { above the coccyx }\end{array}$ & $12(16 \%)$ & $64(84 \%)$ & \\
\hline
\end{tabular}

Patients with isolated sacral dimples were divided into 3 groups based on dimple location relative to the coccyx as measured on sagittal MRI. Fourteen patients were excluded because of an inability to visualize either the coccyx or the dimple. pediatricians (55 [17\%]), urologists (22 [7\%]), and other Children's Hospital specialists (31 [10\%]). Neurosurgical providers routinely offer to screen patients with skin findings suspicious for OSD before an MRI is performed and, though not captured in this study, have a higher threshold for ordering imaging. A trend toward a discrepancy in the OSD rate was seen between neurosurgery providers, whose referrals yielded 28\% (18 of 65) of MRIs positive for OSD, and nonneurosurgery referrals, for which the rate was $19 \%$ (47 of 252). This difference did not reach statistical significance $(\mathrm{p}=0.15)$.

\section{Efficacy of US}

In our population, we identified 61 infants who had undergone lumbar US prior to their MRI. Of these patients, 3 were excluded from analysis due to an inconclusive US report, commonly because of limited visualization due to ossification of the posterior spinal elements, thus leaving a total of 58 patients for our analysis. Thirty-eight $(66 \%)$

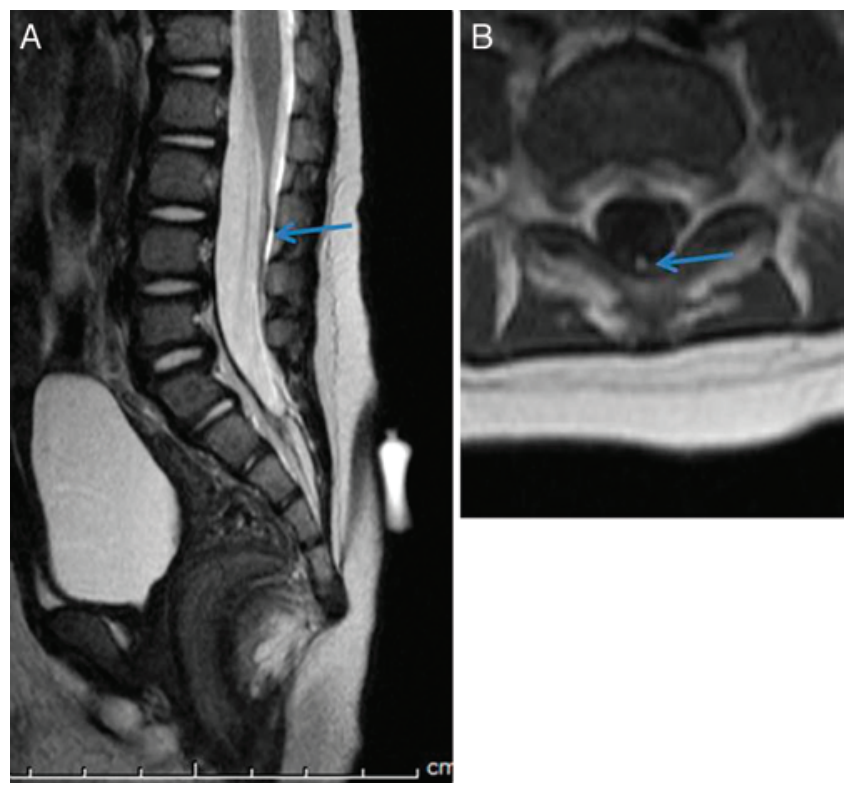

FIG. 2. A sacral dimple was noted at the 6-month well-child check in a patient who was referred for MRI and then a neurosurgery evaluation. Examination by a neurosurgeon revealed "a low-lying dimple just within the gluteal crease and $2.5 \mathrm{~cm}$ above the anus." The dimple measured 13 $\mathrm{mm}$ above the tip of the coccyx on MRI. There was an FFT (arrows) with the conus ending at the L2-3 level. The patient underwent uneventful detethering surgery. Figure is available in color online only. 

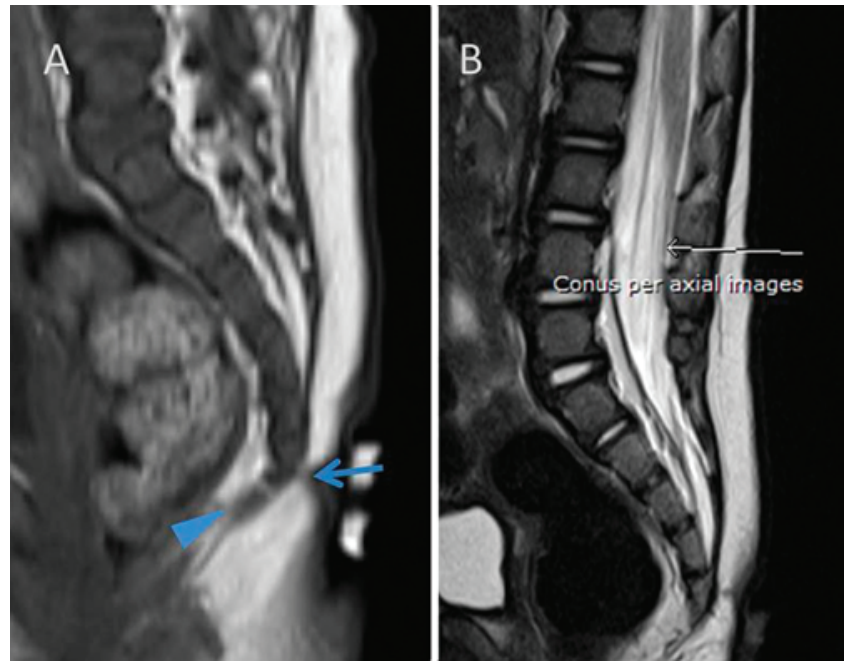

FIG. 3. A "deep sacral dimple" was noted by a child's pediatrician at the 6-month well-child check. Magnetic resonance imaging showed the dimple (arrow, A) at $8 \mathrm{~mm}$ above the coccygeal tip (arrowhead). The conus (arrow, B) ends at L-4 with no clear abnormality of the filum terminale. The child was not referred to neurosurgery and was without neurological symptoms at her 4-year-old well-child check. Figure is available in color online only.

had concern for OSD reported on the US. Among the 20 patients with no evidence of OSD, 11 had a filar cyst, 1 had a fibrous tract extending from a dimple to the soft tissues, and 9 were interpreted as normal. Sixteen $(80 \%)$ of the 20 patients without OSD according to US also had normal MRI studies. The 4 patients (20\%) with false-negative

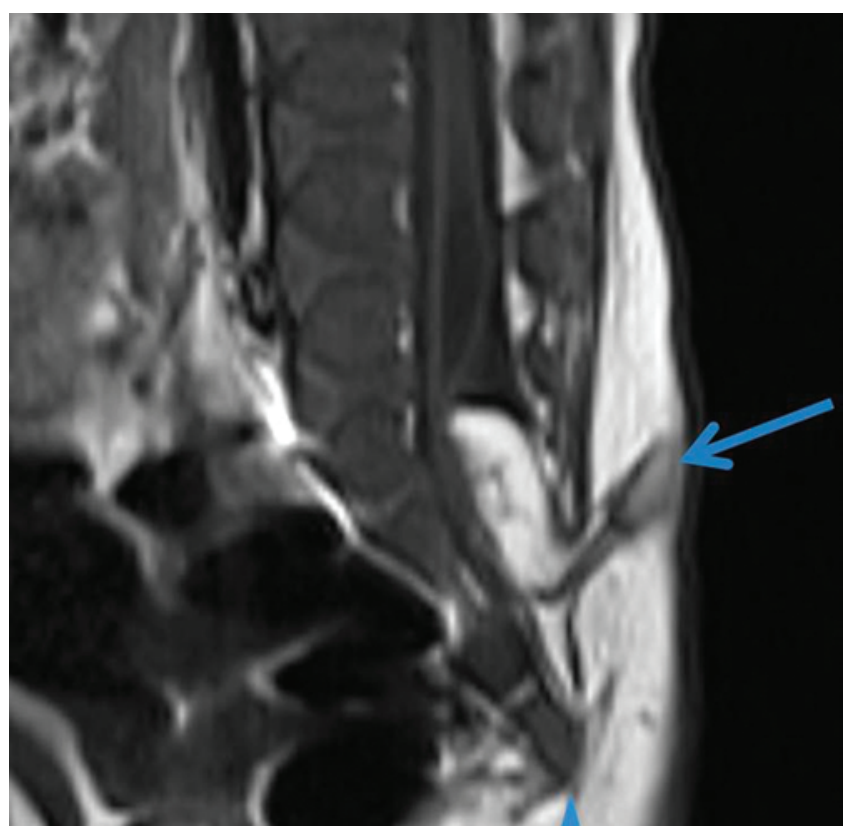

FIG. 4. An otherwise asymptomatic infant was noted to have an isolated dimple above the gluteal crease, overlying the upper sacrum. Ultrasonography at 3 months of age was limited by ossification. Magnetic resonance imaging when the boy was 5 months old showed an LMM with the dimple (arrow) positioned $31 \mathrm{~mm}$ above the coccygeal tip (arrowhead). The boy underwent uneventful detethering surgery. At 4 years postoperation, he had some constipation and bladder instability but was otherwise well. Figure is available in color online only.
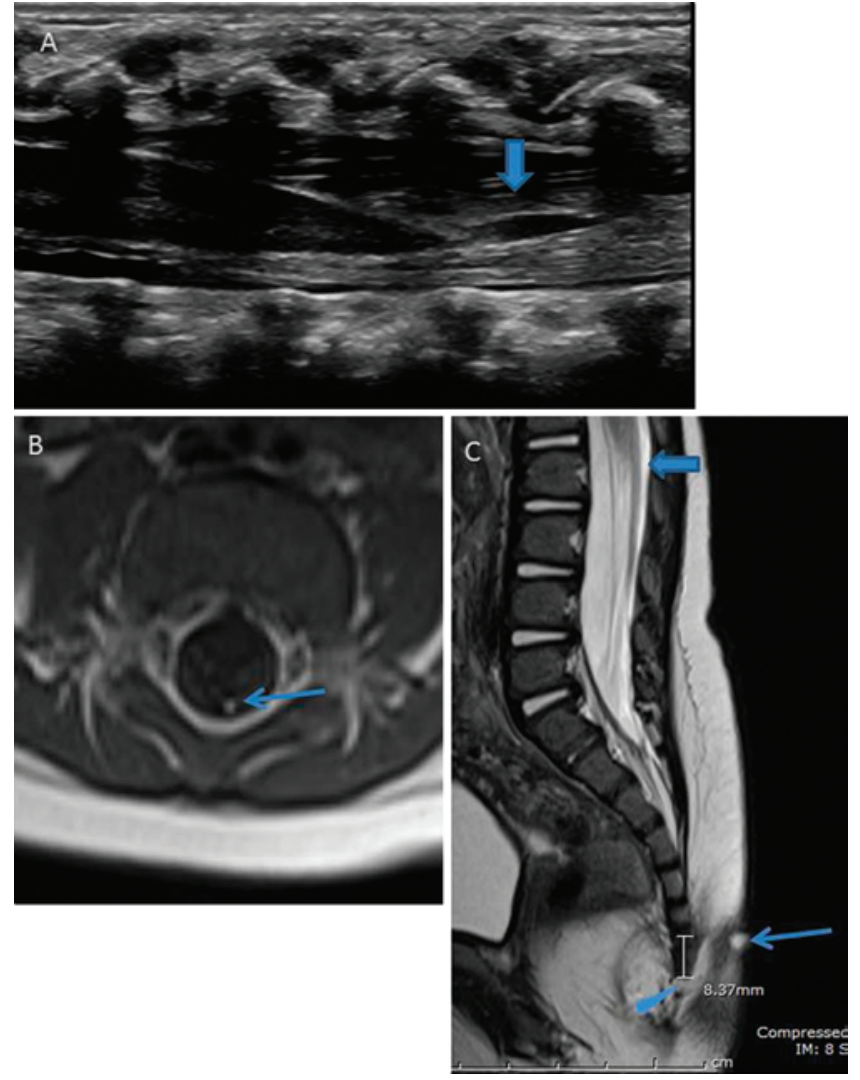

FIG. 5. An infant was referred to neurosurgery at 1 month of age with an ultrasonogram showing a filar cyst (arrow, A) and a dimple "deep within the intergluteal fold" as assessed by a senior neurosurgeon. Magnetic resonance imaging performed when the child was 5 months of age showed an FFT (arrow, B) with the conus ending at the L-2 level (thick arrow, C). The dimple position (thin arrow, C) was $8 \mathrm{~mm}$ above the coccygeal tip (arrowhead). At surgery, the filum was noted to "snap back smartly" when cut. The child was neurologically intact 5.5 years after operation. Figure is available in color online only.

findings (if MRI is used as the standard of reference) all had FFT with a normal position of the conus medullaris.

Ultrasonography in this very select group showed a sensitivity of $86 \%$ and specificity of $55 \%$. The positive predictive value was $66 \%$ with a negative predictive value of $80 \%$.

\section{Discussion}

Spinal cord tethering is a topic rife with controversy and full of vital gaps in our knowledge. The $23 \%$ rate of OSD identified in this study was surprising to us and, indeed, was the reason for undertaking this formal analysis. Our surprise was particularly acute for the group with isolated sacral dimples, a group that in numerous other studies (mostly using US) has been found to have a negligible rate of OSD. ${ }^{1,4,10,13,15,16,18,23}$ It is important to view these results in light of what is known and especially what is not known about the clinical significance of OSD lesions, in particular, in cases of FFT and isolated low-lying conus.

\section{Comparison with Other Studies}

We here report the results of screening infants with 

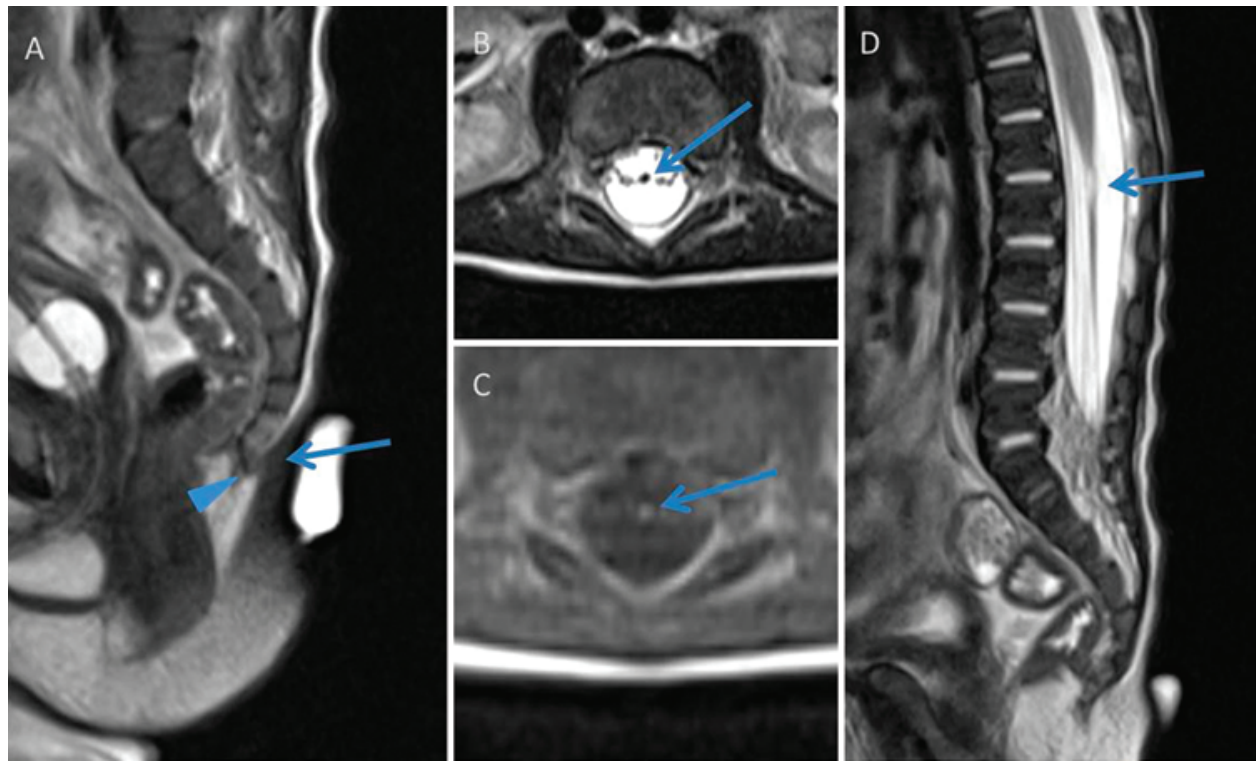

FIG. 6. A patient was referred for MRI and neurosurgery evaluation by a Children's Hospital medical team that noted a dimple. On neurosurgical evaluation, the dimple was " $2 \mathrm{~cm}$ below the gluteal fold" and was believed to be a "simple dimple." On MRI, the dimple (arrow, A) was $2 \mathrm{~mm}$ above the coccygeal tip (arrowhead, A). A short segment of thickening with fatty infiltration of the filum terminal (arrows, B and C) was noted with the conus ending at the L-2 level (arrow, D). This patient was not recommended for surgery. Follow-up was not available. Figure is available in color online only.

modern high-resolution MRI optimized to detect OSD. The MR screening revealed OSD in $23 \%$ of patients. This rate is significantly higher than the $0 \%-3.2 \%$ rate of tethering that has been reported with US screening in comparable large series (Table 5). ${ }^{1,4,10,13,15,16,18,23}$

A number of important differences between MRI and US evaluations for OSD could account for some of the difference in the results. The most striking and probably the most relevant difference is the improved contrast resolution of MRI. A non-fat-saturated T1-weighted MRI will brightly highlight any amount of fat (high signal) within the filum terminale against the dark homogeneous background of the CSF. The in-plane spatial resolution of this image is $0.5 \times 0.6 \mathrm{~mm}$. Additionally, digitization of the images with interpretation on high-resolution monitors allows for significant magnification. In some cases, the fibro- lipoma read on the MR image was seen as only a few pixels of bright signal on the magnified image and probably represents a submillimeter deposit of fat within the filum terminale. Such a small change from normal anatomy is unlikely to be identified by US. The rate at which such small lesions cause clinical symptoms is not known.

There are also differences in the populations referred for US and MRI screening. Ultrasonography is an inexpensive test that never requires sedation, whereas MRI is far more expensive and at times does require sedation. The cost and potential risk of MRI (when sedation is required) probably affect the referral pattern and hence the study population included here compared with those in US series. Referral bias may have a substantial effect on the differences seen in our study and those studies examining the practice of screening with US.

TABLE 5. Selected studies assessing for OSD in broadly defined populations by using different methodologies for detection

\begin{tabular}{|c|c|c|c|c|c|}
\hline $\begin{array}{l}\text { Authors } \\
\& \text { Year }\end{array}$ & Modality & Study Population & Tethering Definition & $\%$ Tethered & Conclusion \\
\hline $\begin{array}{l}\text { Chern et al., } \\
2012\end{array}$ & US & $\begin{array}{l}\text { All infants investigated } \\
\text { for dysraphism }\end{array}$ & $\begin{array}{l}\text { Conus below L2-3, fat in the filum, thick fi- } \\
\text { lum, cyst in the filum, vertebral anomalies, } \\
\text { soft-tissue anomalies }\end{array}$ & $\begin{array}{l}9 \%(106 / 1116) \text { abnor- } \\
\quad \text { mal; } 1.5 \%(17 / 1116) \\
\text { surgically treated }\end{array}$ & \\
\hline $\begin{array}{l}\text { McGovern et } \\
\text { al., } 2013\end{array}$ & US & $\begin{array}{l}\text { All investigations for } \\
\text { dysraphism }\end{array}$ & Not defined & $\begin{array}{l}3.2 \%(7 / 216) \\
\quad \text { tethered; } 8.8 \% \\
(19 / 216) \text { abnormal }\end{array}$ & $\begin{array}{l}\text { Dimple is a poor marker } \\
\text { of dysraphism }\end{array}$ \\
\hline Current study & MRI & $\begin{array}{l}\text { All investigations for } \\
\text { dysraphism }\end{array}$ & $\begin{array}{l}\text { Conus below L2-3, fibrolipoma, dermal si- } \\
\text { nus extending to thecal sac, spinal lipoma }\end{array}$ & $\begin{array}{l}23.4 \%(122 / 522) \\
\quad \text { tethered }\end{array}$ & $\begin{array}{l}\text { OSD commonly identified } \\
\text { when screening w/ MRI }\end{array}$ \\
\hline $\begin{array}{l}\text { McLendon et } \\
\text { al., } 1988\end{array}$ & Autopsy & $\begin{array}{l}\text { Adult autopsy, no neural } \\
\text { symptoms }\end{array}$ & Fat in the filum grossly or by microscopy & $19 \%(9 / 47)$ & $\begin{array}{l}\text { Fibrolipomas occur } \\
\text { incidentally }\end{array}$ \\
\hline $\begin{array}{l}\text { Lendon \& Em- } \\
\quad \text { ery, } 1968\end{array}$ & Autopsy & $\begin{array}{l}\text { Infant necropsy w/o } \\
\text { neurological anomaly }\end{array}$ & Filum lipoma grossly or by microscopy & $5.6 \%(5 / 90)$ & $\begin{array}{l}\text { Fibrolipomas occur } \\
\text { incidentally }\end{array}$ \\
\hline
\end{tabular}


TABLE 6. Comparison of large studies evaluating rate of OSD in patients with sacral dimple

\begin{tabular}{|c|c|c|c|c|c|}
\hline $\begin{array}{l}\text { Authors } \\
\& \text { Year }\end{array}$ & Modality & Study Population & Tethering Definition & $\%$ Tethered & Conclusion \\
\hline $\begin{array}{r}\text { Ben-Sira et } \\
\text { al., } 2009\end{array}$ & US & $\begin{array}{l}\text { Simple dimple w/in } 25 \\
\text { mm of anus * }\end{array}$ & Conus L-3 body, filum $>2 \mathrm{~mm}$ thick & $\begin{array}{l}0 \text { of } 109 \text { (106 normal, } 3 \\
\text { inconclusive }\end{array}$ & Simple dimple is benign lesion \\
\hline $\begin{array}{c}\text { Chern et al., } \\
2012\end{array}$ & US & Sacral dimple* & $\begin{array}{l}\text { Conus below L2-3, fat in the filum, } \\
\text { thick filum, cyst in the filum, } \\
\text { vertebral anomalies, soft-tissue } \\
\text { anomalies }\end{array}$ & $\begin{array}{l}6.5 \%(42 / 643) \text { abnormal } \\
\text { US; } 0.8 \%(5 / 643) \text { surgi- } \\
\text { cally treated }\end{array}$ & \\
\hline $\begin{array}{l}\text { McGovern et } \\
\text { al., } 2013\end{array}$ & US & Dimple alone* & Not defined & $1.3 \%(2 / 149)$ & $\begin{array}{l}\text { Dimple is poor marker of } \\
\text { dysraphism }\end{array}$ \\
\hline $\begin{array}{l}\text { Kucera et } \\
\text { al., } 2015\end{array}$ & US & Simple sacral dimple & $\begin{array}{l}\text { Conus below L2-3, decreased } \\
\text { conus motion, abnormal filum, } \\
\text { Intraspinal mass, osseous dysra- } \\
\text { phism, sinus leading to thecal sac }\end{array}$ & $\begin{array}{l}3.4 \%(133 / 3884) \text { abnor- } \\
\quad \text { mal; } 2 \%(76 / 3884) \text { teth- } \\
\text { ered; } 0.13 \%(5 / 3884) \\
\text { surgically treated }\end{array}$ & \\
\hline $\begin{array}{l}\text { Harada et } \\
\text { al., } 2014\end{array}$ & MR & $\begin{array}{l}\text { Intergluteal dimples end- } \\
\text { ing at coccyx ( } 8 \% \mathrm{w} / \\
\text { deviated gluteal fold or } \\
\text { hemangioma as well) }\end{array}$ & Conus below L-3 body, FFT & $16.7 \%(14 / 84)$ & $\begin{array}{l}\text { Deep dimples more commonly } \\
\text { associated w/ tethering; all } \\
\text { had filar anomalies }\end{array}$ \\
\hline $\begin{array}{l}\text { Current } \\
\text { study }\end{array}$ & MR & Isolated dimple* & $\begin{array}{l}\text { Conus below L2-3, fibrolipoma, } \\
\text { dermal sinus extending to thecal } \\
\text { sac, spinal lipoma }\end{array}$ & $20 \%(46 / 235)$ & $\begin{array}{l}\text { No relationship btwn level of } \\
\text { dimple \& rate of tethering; } \\
\text { almost all are filar anomalies }\end{array}$ \\
\hline
\end{tabular}

* Sacral dimple population is a subgroup of a larger investigation.

In the US series most comparable to our MRI series, Chern found that 1273 infants underwent US over a 5-year period, ${ }^{4}$ whereas we found 522 MRI studies over a 6-year period, perhaps reflecting some reluctance to refer for MRI. Additionally, some children in our referral area would have undergone US screening, further biasing the referral decision.

Magnetic resonance imaging is typically performed in patients at an older age, raising the possibility that fat within the filum terminale forms or expands during the early months of development, much as body adipose tissue typically increases in the early months of infancy. This theory is supported by the observation that adipose tissue within intramedullary lipomas and lipomatous malformations associated with dysraphism has been reported to enlarge with an increase in body adipose tissue. ${ }^{6,20}$

It is also possible that the development of lumbar skin and soft tissues in the first months of life allow a clearer assessment of whether dimples and other lesions are truly pathological. The later age recommended for MRI allows better appreciation of the anatomy and better toleration of sedation when needed. The mean age at imaging in our study was 6.2 months. Ultrasonography, on the other hand, is typically performed as young as is feasible, often in the newborn nursery. Ultrasonography is not possible once the posterior spinal elements have ossified, which usually has occurred by 6 months of age. The mean age at imaging in the Chern et al. and Ben-Sira et al. US studies was 1.4 and 1.6 months, respectively. ${ }^{1,4}$

\section{Dimples}

It is worth looking at the group of patients scanned for isolated dimples since these markers are the most common indication for screening in virtually all series re- ported. ${ }^{4,10,13,15,18,23}$ Dimples are particularly important because they are present in $2 \%-4 \%$ of all neonates. ${ }^{10,15}$ In our series, $20 \%$ of patients with an isolated dimple had OSD, with no significant difference between those with low dimples (23\% in dimples within $11 \mathrm{~mm}$ of the coccyx) and those with dimples higher up. In the only other series examining MRI screening of infants with intergluteal dimples, Harada et al. found $16.7 \%$ of 84 patients to have FFT (Table 6). ${ }^{9}$ No other OSD lesions were identified. In their series, deep dimples were more commonly associated with OSD. Ben-Sira et al. prospectively collected data on 109 infants with dimples within the gluteal crease who had been screened with US. ${ }^{1}$ Occult spinal dysraphism was identified in none. Chern et al. retrospectively studied 643 screening US studies of infants with dimples, identifying $0.8 \%$ with OSD that required surgery. ${ }^{4}$ Kucera et al. reviewed 10 years of screening US studies performed for dimples and found a $2 \%$ rate of OSD using a definition of OSD identical to that in our study. ${ }^{16}$

A number of these studies have concluded that various features of a dimple predict OSD including deeper dimples, ${ }^{9,10}$ wider dimples, ${ }^{15}$ dimples associated with other stigmata, ${ }^{15,18,23}$ and, most prevalently, dimples over the sacrum rather than the coccyx (described variously as above the gluteal crease or $>2.5 \mathrm{~cm}$ from the anus).,15 The retrospective nature of our case series limits our ability to evaluate many of these features; however, our data showed no correlation between OSD and dimple height when using distance from the coccygeal tip as measured on MRI as a surrogate for the relation to the anus, gluteal crease, or sacrum. The presence of additional cutaneous markers likewise showed no correlation with OSD. It is also notable that a variety of medical providers referred our subjects with dimples for MRI, presumably with different criteria 
for referral, but that no difference in the rate of dysraphism could be identified based on the referring provider.

\section{Prevalence and Natural History of FFT}

A high rate of potentially tethering OSD lesions was found in this study, but the clinical significance of such lesions has not been well studied. There is significant evidence that FFTs can be benign. One such line of evidence is the occurrence of fat in the filum terminale in asymptomatic individuals. ${ }^{2,5,14,17,19}$

Two MRI-based studies have addressed this issue. Kesler et al. reviewed 100 spine MR images obtained in children presenting at a mean age of 7.5 years with brain tumors. ${ }^{14}$ Scans were optimized to detect metastatic tumors rather than OSD. They found 2 FFTs with no conus below the L-2 body. Brown et al. reviewed 100 randomly selected lumbar MRI studies, 98 of which were obtained in adults, and found 4 FFTs. ${ }^{2}$ The clinical scenarios in those patients were disc herniation (2 patients), discitis (1 patient), and spinal stenosis (1 patient).

Autopsy studies have shown similar rates of FFT. Lendon and Emery examined the filum terminale grossly and with microscopy in 90 infant necropsies without known neurological abnormalities and found 5 fibrolipomas (5.6\%). ${ }^{17}$ McLendon et al. examined the filum microscopically after serial sectioning in 47 adult autopsies and found 9 fibrolipomas, a rate of $19 \% .^{19}$

Prospective study of the natural history of OSD lesions has been limited. Such study faces many barriers to completion, including the need for decades-long follow-up and concern about the clinical equipoise of nontreatment. ${ }^{24}$ Cools et al. attempted to understand the natural history of FFT with an imaging database study. ${ }^{5}$ They electronically searched the imaging reports of over 50,000 lumbar MRI studies for key terms referencing fibrolipomas, and 436 patients with FFT were revealed. The patient records were reviewed for the clinical significance of the fibrolipoma and for the development of symptoms over time. Twentytwo patients $(5 \%)$ with symptoms of TCS were identified. Twelve percent (52 of 436) of the entire cohort underwent surgery. Follow-up documentation was available for 249 of the nonsurgical patients with a mean time of 3.5 years. Only 1 patient developed TCS symptoms.

Many of the OSD lesions identified in the current study were quite subtle and unlikely to be identified without dedicated MRI sequences optimized for that purpose. The use of digitized images displayed on high-resolution monitors with the ability to magnify the area of interest probably allowed the detection of some lesions that would not have been seen using printed film technology (as was more prevalent before the year 2000). Some fibrolipomas were visualized as only a pixel or two per axial slice. Many did not extend the full length of the filum terminale. Thirtynine percent of the filar abnormalities identified in the present study were not surgically treated.

\section{Study Limitations}

The major limitation of this study is its retrospective nature. The available data gleaned from chart review do not allow us to assess a number of potentially important factors about the cutaneous stigmata of our patients, specifically, the depth and width of the dimples imaged. Additionally, the number of patients undergoing US in this study was quite small and likely highly selected. This greatly influences the pretest bias of the subsequent MR imaging and limits the conclusions that can be drawn about the direct comparison of US to MRI in diagnosing spinal tethering lesions.

\section{Conclusions}

The prevalence of OSD identified with modern highresolution MRI screening is significantly higher than that reported with US screening, particularly in patients with sacral dimples. This difference may in part be the result of different indications for imaging. The great majority of OSD lesions identified are FFT and low conus. The clinical significance of such lesions remains unclear, although a higher identified prevalence supports a less aggressive surgical approach.

\section{References}

1. Ben-Sira L, Ponger P, Miller E, Beni-Adani L, Constantini S: Low-risk lumbar skin stigmata in infants: the role of ultrasound screening. J Pediatr 155:864-869, 2009

2. Brown E, Matthes JC, Bazan C III, Jinkins JR: Prevalence of incidental intraspinal lipoma of the lumbosacral spine as determined by MRI. Spine (Phila Pa 1976) 19:833-836, 1994

3. Bui CJ, Tubbs RS, Oakes WJ: Tethered cord syndrome in children: a review. Neurosurg Focus 23(2):E2, 2007

4. Chern JJ, Aksut B, Kirkman JL, Shoja MM, Tubbs RS, Royal SA, et al: The accuracy of abnormal lumbar sonography findings in detecting occult spinal dysraphism: a comparison with magnetic resonance imaging. J Neurosurg Pediatr 10:150-153, 2012

5. Cools MJ, Al-Holou WN, Stetler WR Jr, Wilson TJ, Muraszko KM, Ibrahim M, et al: Filum terminale lipomas: imaging prevalence, natural history, and conus position. J Neurosurg Pediatr 13:559-567, 2014

6. Giudicelli Y, Pierre-Kahn A, Bourdeaux AM, de Mazancourt P, Lacasa D, Hirsch JF: Are the metabolic characteristics of congenital intraspinal lipoma cells identical to, or different from normal adipocytes? Childs Nerv Syst 2:290-296, 1986

7. Golonka NR, Haga LJ, Keating RP, Eichelberger MR, Gilbert JC, Hartman GE, et al: Routine MRI evaluation of low imperforate anus reveals unexpected high incidence of tethered spinal cord. J Pediatr Surg 37:966-969, 2002

8. Gourineni P, Dias L, Blanco R, Muppavarapu S: Orthopaedic deformities associated with lumbosacral spinal lipomas. J Pediatr Orthop 29:932-936, 2009

9. Harada A, Nishiyama K, Yoshimura J, Sano M, Fujii Y: Intraspinal lesions associated with sacrococcygeal dimples. J Neurosurg Pediatr 14:81-86, 2014

10. Henriques JG, Pianetti G, Henriques KS, Costa P, Gusmão S: Minor skin lesions as markers of occult spinal dysraphismsprospective study. Surg Neurol 63 (Suppl 1):S8-S12, 2005

11. Hertzler DA II, DePowell JJ, Stevenson CB, Mangano FT: Tethered cord syndrome: a review of the literature from embryology to adult presentation. Neurosurg Focus 29(1):E1, 2010

12. Hoffman HJ, Hendrick EB, Humphreys RP: The tethered spinal cord: its protean manifestations, diagnosis and surgical correction. Childs Brain 2:145-155, 1976

13. Hughes JA, De Bruyn R, Patel K, Thompson D: Evaluation of spinal ultrasound in spinal dysraphism. Clin Radiol 58:227233, 2003

14. Kesler H, Dias MS, Kalapos P: Termination of the normal conus medullaris in children: a whole-spine magnetic resonance imaging study. Neurosurg Focus 23(2):E7, 2007 
15. Kriss VM, Desai NS: Occult spinal dysraphism in neonates: assessment of high-risk cutaneous stigmata on sonography. AJR Am J Roentgenol 171:1687-1692, 1998

16. Kucera JN, Coley I, O'Hara S, Kosnik EJ, Coley BD: The simple sacral dimple: diagnostic yield of ultrasound in neonates. Pediatr Radiol 45:211-216, 2015

17. Lendon RG, Emery JL: Forking of the central canal in the equinal cord of children. J Anat 106:499-505, 1970

18. McGovern M, Mulligan S, Carney O, Wall D, Moylett E: Ultrasound investigation of sacral dimples and other stigmata of spinal dysraphism. Arch Dis Child 98:784-786, 2013

19. McLendon RE, Oakes WJ, Heinz ER, Yeates AE, Burger PC: Adipose tissue in the filum terminale: a computed tomographic finding that may indicate tethering of the spinal cord. Neurosurgery 22:873-876, 1988

20. Muraszko K, Youkilis A: Intramedullary spinal tumors of disordered embryogenesis. J Neurooncol 47:271-281, 2000

21. O'Neill BR, Yu AK, Tyler-Kabara EC: Prevalence of tethered spinal cord in infants with VACTERL. J Neurosurg Pediatr 6:177-182, 2010

22. Ponger P, Ben-Sira L, Beni-Adani L, Steinbok P, Constantini $S$ : International survey on the management of skin stigmata and suspected tethered cord. Childs Nerv Syst 26:1719_ 1725,2010

23. Robinson AJ, Russell S, Rimmer S: The value of ultrasonic examination of the lumbar spine in infants with specific reference to cutaneous markers of occult spinal dysraphism. Clin Radiol 60:72-77, 2005

24. Steinbok P, Garton HJ, Gupta N: Occult tethered cord syndrome: a survey of practice patterns. J Neurosurg 104 (5 Suppl):309-313, 2006

25. Tani S, Yamada S, Knighton RS: Extensibility of the lumbar and sacral cord. Pathophysiology of the tethered spinal cord in cats. J Neurosurg 66:116-123, 1987

26. Tu A, Steinbok P: Occult tethered cord syndrome: a review. Childs Nerv Syst 29:1635-1640, 2013

27. Tubbs RS, Wellons JC III, Iskandar BJ, Oakes WJ: Isolated flat capillary midline lumbosacral hemangiomas as indicators of occult spinal dysraphism. J Neurosurg 100 (2 Suppl Pediatrics):86-89, 2004

\section{Disclosures}

The authors report no conflict of interest concerning the materials or methods used in this study or the findings specified in this paper.

\section{Author Contributions}

Acquisition of data: O'Neill, Gallegos, Herron. Analysis and interpretation of data: O'Neill, Gallegos, Herron, Stence, Hankinson, Wilkinson, Handler. Drafting the article: O'Neill, Gallegos. Critically revising the article: O'Neill, Stence, Hankinson, Wilkinson, Handler. Reviewed submitted version of manuscript: O'Neill, Stence, Hankinson, Wilkinson, Handler. Approved the final version of the manuscript on behalf of all authors: O'Neill. Statistical analysis: Palmer. Administrative/technical/material support: Handler. Study supervision: O’Neill, Handler.

\section{Correspondence}

Brent R. O'Neill, Children's Hospital Colorado, Department of Neurosurgery, 13123 E 16th Ave., B-330, Aurora, CO 80045. email: brent.o'neill@childrenscolorado.org. 